\title{
Improvement reliability of cutting ceramic through use of damping system and nanostructured multilayered composite coatings
}

\author{
Alexey Vereschaka ${ }^{1, *}$, Boris Mokritskii ${ }^{2}$, Alexey Krapostin ${ }^{3}$, Nikolay Sitnikov ${ }^{4,5}$, and Gaik Oganyan ${ }^{1}$ \\ ${ }^{1}$ Moscow State Technological University STANKIN, Vadkovsky per. 1, Moscow 127994, Russia \\ ${ }^{2}$ Komsomolsk-na-Amure State Technical University, 27, Komsomolsk-na-Amure 681013, Russia \\ 3 JSC "Plant named after G.K. Korolev", St. Zvereva-22, Ivanovo 153003, Russia \\ 4 Federal State Unitary Enterprise "Keldysh Research Center", Onezhskaya St. 8, Moscow 125438, Russia \\ ${ }^{5}$ National Research Nuclear University MEPhI (Moscow Engineering Physics Institute), Kashirskoe shosse 31, \\ Moscow 115409, Russia
}

Received: 20 June 2016 / Accepted: 28 December 2018

\begin{abstract}
This paper considers new avenues of improving the efficiency of machining hardened steels using damping devices and nanostructured multilayered composite coatings deposited on ceramic cutting tools with innovative arc-PVD processes with filtration of vapor-ion flow. A developed technology allows reducing peak stresses arising during cutting-in and providing improved reliability of ceramic tools. It is observed that the formation of modifying coatings on an edge ceramic tool in machining of hardened steels with HRC $>50$ under the conditions of damping can reduce the coefficient of tool failure variation down to 0.3 , and that improves the ability to predict failure of ceramic tools and allows recommending ceramic tools for the use in automated production.
\end{abstract}

Keywords: Cutting ceramic / wear resistant coating / machining of hardened steel / arc-PVD / damping device

\section{Introduction}

Ceramic tool materials are characterized by a number of important physical and mechanical properties such as high chemical inactivity, enhanced hardness, heat resistance and, respectively, increased wear resistance, and that ensures high performance of the cutting process in the use of a ceramic tool. An additional argument in favor of tool made of cutting ceramic (CC) is the absence of scarce and expensive elements in the composition of $\mathrm{CC}$, and that reduces the cost of the tool in the cutting process [1].

It should also be noted that the tools of CC may be used at high cutting speeds without the use of cutting fluid (CF), and that fact significantly reduces the negative impact on the environment and meets the environmental requirements for modern technological processes.

\footnotetext{
* e-mail: ecotech@rambler.ru
}

Apart from its significant advantages, cutting ceramic is also characterized by a number of shortcomings, which may include relatively low resistance of the ceramic material to failure when exposed to variable thermal and mechanical loads and low plastic strength margin (resistance to elastic fracture) and increased tendency to cracking [1-3].

At present, extensive knowledge is accumulated in the field of performance of cutting tools made of high-speed steel and carbides; however, this knowledge is almost impossible to use in the analysis of performance of tools made of ceramic materials. The sphere of application of ceramic tool materials is also very different from the sphere of application of cutting tools made of high-speed steel and carbides. In general, the specific sphere of application of tools made of $\mathrm{CC}$ is determined by the strong difference in mechanical and thermal properties of cutting ceramic and traditional tools materials, as well as the specifics of physical and chemical interaction of tool material and the material being machined. In particular, the extension of the application of cutting ceramic requires improvement of characteristics of toughness and crack resistance $[1,2,4]$. 
The results of the studies devoted to improvement of various properties of cutting ceramic [1-4] prove the convincing progress in solution of the challenge to improve the properties of cutting ceramic. Substitution of carbide tool with coated tool equipped with cutting inserts of $\mathrm{CC}$ with coating reduces the machining cost by $70-75 \%$ [3].

At present, the modification of surface properties of cutting inserts of CC through deposition of coatings is one of the most effective ways to improve their performance properties.

The coatings of different compositions, structures and properties applied to the working surfaces of ceramic cutting inserts provide directional control over contact processes, thermal state of the cutting tool and its wear rate $[1,4]$.

Low cracking resistance of cutting ceramic causes formation of cracks, which because of the absence of plastic binding phase meet no barriers that can slow down or stop their development. This phenomenon results in micro- or macrochipping of tool contact areas at the stages of running-in or initial phase of steady wear, resulting in tool failure because of brittle fracture. Accumulation and development of pores prepare the process of coalescence when as a result of interaction pores begin to grow rapidly toward each other and merge, thus forming cracks. One of the key reasons resulting in the formation of cracks and subsequent failure of ceramic tool is in high vibrations and shock loads.

Various damping devices are widely used in metal cutting, and the major task of such devices is primarily to reduce chatter during cutting. The damping devices were offered in various designs. In particular, references $[5,6]$ consider the method of reduction of chatter by using permanent magnets. The main idea was that the magnet will provide effective damping by attracting the steel tool shank and restricting its vertical vibratory motion during cutting operations. Analysis of the recorded vibration signals in the frequency domain indicated that significant reduction in the vibration amplitude, as much as $86 \%$, was obtained with magnetic damping. It was found that tool wear is reduced considerably by a maximum of $87.8 \%$ with the magnetic damping method. References $[7,8]$ consider tuned mass dampers as simple and efficient devices for suppression of machine tool chatter. Damping is generated in the damper by eddy currents, altogether providing quite linear and predictable behavior. The main idea of reference [9] is to address the issue of chatter instability by proposing a vibration reduction methodology through the use of embedded piezoelectric patches in the tool holder connected to a passive shunt electrical circuit. This circuit is responsible for energy dissipation providing extra damping to the system. The strategy is numerically and experimentally tested in turning/ boring operations.

The purpose of this study is to provide the reliability of mineral-ceramic cutting tool for continuous cutting of workpieces with enhanced hardness based on the use of nanostructured multilayered coatings and dampening effect of cutting system.

\section{Study of structure of cutting tool failures}

\subsection{Influence of degree of cutting tool wear on failure rate}

Reference [10] studied the dependence of wear of cutting tool, equipped with cutting inserts of CC, under various cutting conditions and geometrical parameters. The preliminary finding that flank wear land does not exceeding $\mathrm{VB}_{c}=0.2-0.25 \mathrm{~mm}$ should be taken as a criterion for blunting of a ceramic tool. When the above value of flank wear land is exceeded, the probability of sudden tool failure increases sharply and roughness of machined surface increases. Furthermore, reference [11] found that an increase in flank wear land of ceramic cutting inserts over $0.25 \mathrm{~mm}$ contributes to a significant change in the thermal condition of the cutting edge and extension of isotherms on flank face, which results in significant increase in wear rate.

According to the methodology offered by the author of reference [12] to improve the efficiency of the study, several reference points of tool wear should be selected to determine the nature and rate of its failures. To do that, after a specified period of time $(45 \mathrm{~s})$, flank wear land $\mathrm{VB}_{c}$ was measured, and the general state of the tool was studied with a metallographic microscope. Ceramic inserts were studied after the procedures of etching under acid media of pickups of metal being machined in the wear centers of rake and flank faces, and after that, the tests were conducted to study the dependence of number of failures from the value of flank wear land. The test results were used to determine the random failure distribution patterns depending on the value of flank wear face. Meanwhile, the experiments were terminated with increase of roughness of the machined surfaces of heat-treated steel workpieces, exceeding $R_{\mathrm{a}}=0.6-$ $0.8 \mu \mathrm{m}$.

Thus, the study involved the tests to find out the parameters characterizing the reliability of ceramic tool depending on the number of its cutting-ins in the surface of heat-treated steel workpiece being machined, at depth of cut $a_{p}=0.2-0.3 \mathrm{~mm}$, cutting speed $V_{c}=600 \mathrm{~m} / \mathrm{min}$ and feed $f=0.1 \mathrm{~mm} / \mathrm{rev}$, which is typical for finishing operations with ceramic tool. The working conditions are presented in Table 1.

During the tests, the total number of cutting edges of ceramic cutting inserts involved in cutting reached 100 pieces (Fig. 1).

It was observed that failure of ceramic cutting tool may occur at all wear phases. Meanwhile, during the experiments, occasional failures at the running-in wear phase were excluded.

\subsection{Study of influence of machining phases on failure rate}

Using the above theoretical provisions and the analysis of the data of the available research on development of the main crack and chips (brittle fracture) of a ceramic tool, the study carried out tests on the influence of machining phases on failure of ceramic tools. 
Table 1. The working conditions at cutting tests.

Cutting tool material

Cutting tool geometry

Coating composition and structure

Workpiece material properties

Cooling conditions

Machine-tool

Cutting conditions

Number of trials at cutting tests
Cutting ceramic $\mathrm{Al}_{2} \mathrm{O}_{3}-\mathrm{TiC}$

$K=75^{\circ} ; K_{1}=15^{\circ} ; \gamma=\alpha=5^{\circ} ; \lambda=0 ; r=0.8 \mathrm{~mm}$

$\mathrm{Ti}-(\mathrm{TiAl}) \mathrm{N}-(\mathrm{TiAlCr}) \mathrm{N}$

Ti-TiAlN-(ZrNbTiAl)N

Hardened steels C90E2U, C45, 37Cr4 with hardness of HRC 48-52

Dry cutting

Lathe CU 500 MRD

$V_{c}=600 \mathrm{~m} / \mathrm{min}, f=0.1 \mathrm{~mm} / \mathrm{rev}, a_{p}=0.1-0.25 \mathrm{~mm}$ $50-100$

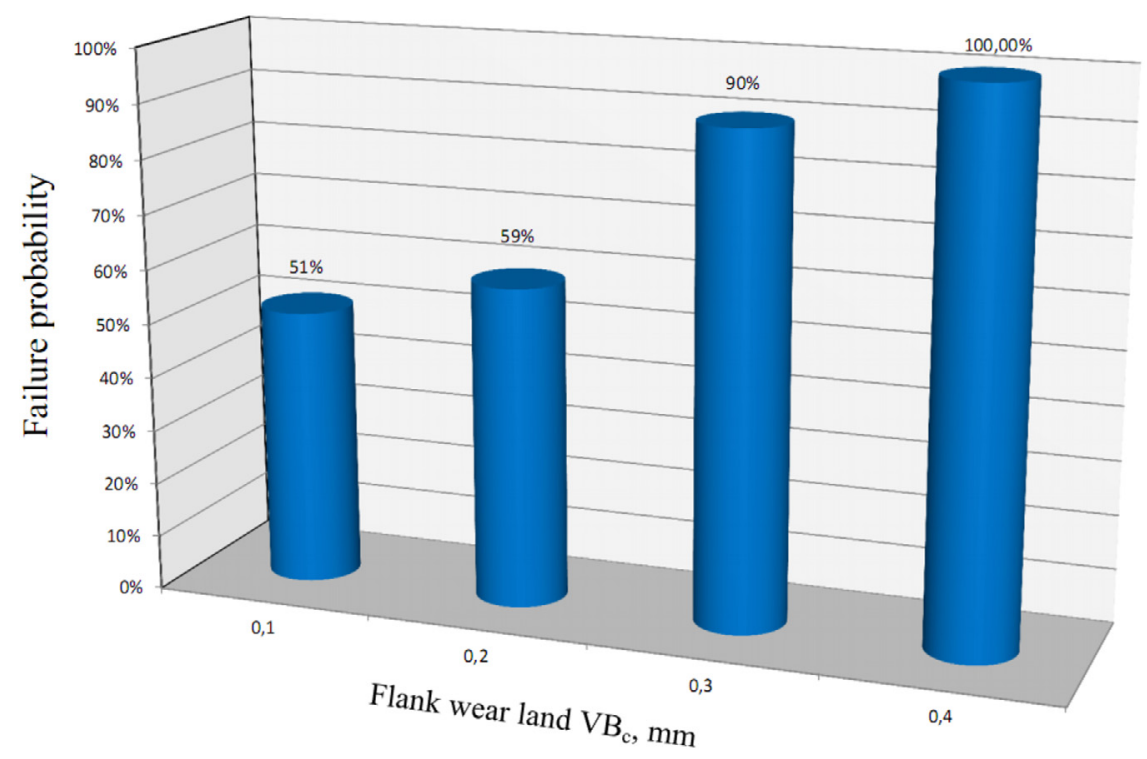

Fig. 1. Dependence of failure probability of the value of flank wear land of cutting inserts of $\mathrm{Al}_{2} \mathrm{O}_{3}$-TiC in turning of hardened steel C90E2UHRC 52 at $V_{c}=600 \mathrm{~m} / \mathrm{min} ; f=0.1 \mathrm{~mm} / \mathrm{rev}, a_{p}=0.2-0.3 \mathrm{~mm}$.

It is found that in action of external thermomechanical stresses on contact areas of cutting tool, as well as in development of wear centers, particularly on flank face, the ceramic tool is exposed to complex stress effect, resulting in brittle fracture of its contact areas and cutting edge $[13-18]$.

During the tests of 100 cutting edges, the study found the most hazardous machining areas in which tool failure occurs with maximum intensity (Fig. 2).

Bar charts of ceramic tool failures (see Fig. 2) indicate the prevalence of failures at the moment of tool cutting-in into a workpiece. It is observed that the number of cuttingins and withdrawals of the tool from working area has a decisive influence on the number of its failures. The major portion of failures (77\%) during the tool performance occurs at cutting-ins and withdrawals of the tool from working area and that indicates high embrittlement and low plasticity, weak interatomic bindings of standard ceramic tool of $\mathrm{Al}_{2} \mathrm{O}_{3}$-TiC.

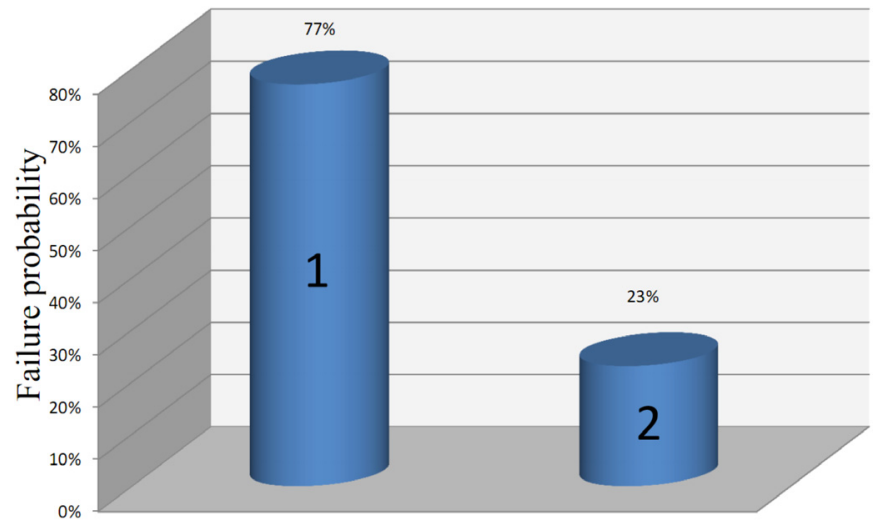

Fig. 2. Dependence of number of failures from phase of machining with tool equipped with cutting inserts of $\mathrm{Al}_{2} \mathrm{O}_{3}$ - TiC in turning of hardened steel C90E2U HRC $52\left(V_{c}=600 \mathrm{~m} / \mathrm{min}, f=0.1 \mathrm{~mm} /\right.$ rev, $\left.a_{p}=0.2-0.25 \mathrm{~mm}\right) .1$-cutting-ins and withdrawals of the tool from working area; 2 -continuous turning. 
In this regard, it has been suggested that precisely at the moment of cutting-in and withdrawal of a tool from the cutting area, the peak stresses occur on its surface, and they are the main cause of formation and development of main cracks, resulting in brittle chipping of cutting edge of a ceramic insert.

Cutting ceramic well withstands high temperatures, but extremely negatively perceives thermal stresses, formed under the influence of temperature gradients [19]. However, in turn, it is impossible to exclude the influence of shock loads, critical stresses and vibration processes affecting the tools. Therefore, it can be concluded that the major causes of ceramic tool failures during operation are in uncertainty of the operational load, arising during cutting, and the role of thermomechanical stress [11].

Thus, it can be concluded that tool failure can also occur in residual stresses and microcracks formed, which arise in the tool during manufacture, and the stresses arising in operating loads result in formation and development of microcracks. The development of microcracks results in separation of wear particles from the tool surface or chipping.

\section{Development of structure of damping device, smoothing peak stresses in cutting-in of ceramic tool into machining area}

Significant reduction in lengths of full and, in particular, plastic contact, convergence of boundaries of area of major deformations, decrease in dimensions of contact deformations and specific work of plastic deformation $A_{\mathrm{p}}$, as well as reduction of contact stresses $\sigma_{\gamma}$ and $\tau_{\gamma}$ contribute to stabilization of plastic deformation and chip formation.

As is known, stabilization of the plastic deformation process with simultaneous reduction in energy consumption on plastic deformation and friction facilitate cutting stability [20].

The cutting process may invoke periodic vibrations of separate elements of machine-tool-workpiece system (MTWS) of high frequency, which results in

- tool chipping,

- loss of accuracy and roughness of surface being machined and

- loss of efficiency.

Particular problems arise during the machining of hardto-cut materials, where cutting takes place in an unstable mode. The research in this direction shows sufficiently large amplitude of vibrations induced in cutting-in and withdrawal of the tool cutting edge of the contact with the material being machined. One of the methods to eliminate this type of vibration is to switch off or decrease feed of cutting at the exit from the surface being machined, and that produces a positive effect on the tool reliability and a negative effect on roughness of the surface machined.

Metal cutting is a complex nonlinear dynamical process. The self-excited vibration caused by the regenerative effect, usually called chatter, can be created during machining by increasing one cutting parameter while

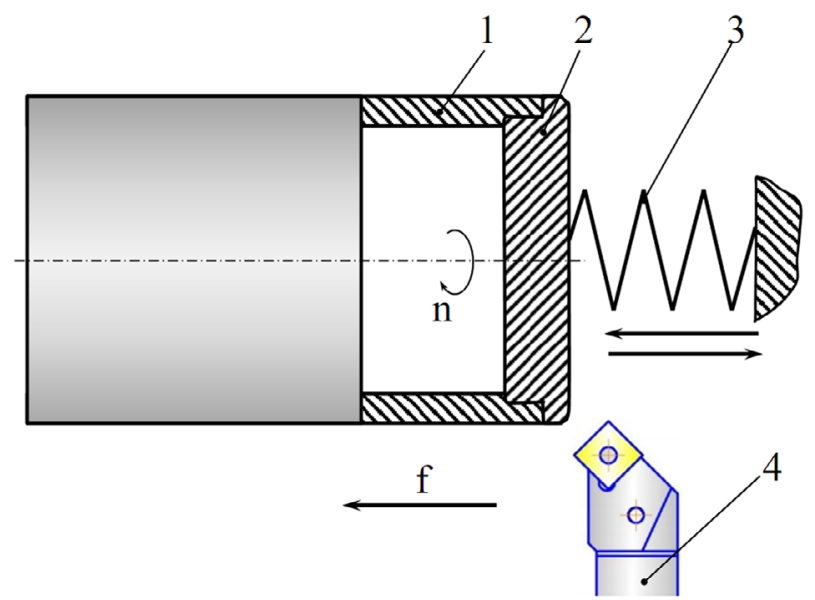

Fig. 3. Principal scheme of damping device: 1 - the workpiece being machined; 2 - the disk damping peak stresses in cutting-in of the tool; 3 - the damper of extension vibrations of a workpiece; 4 - the cutting tool equipped with cutting inserts of CC.

keeping all other cutting parameters constant. It is known [21-23] that the greatest difficulty in machining of hard materials arises from self-excited free vibrations, characterized by lack of external periodic force, exciting the vibration process. The frequency of vibrations does not generally depend on the cutting conditions and dimensions of the tool cutting edge, and it equals to the natural frequency of the system MTWS. During the study of vibrations, it is assumed to divide the MTWS system into several components, including power source, excitation mechanism, vibrating system and stabilizer of amplitudes.

One of the ways to compensate excited vibrations during the cutting process is to reduce the value of exciting forces. So, in intermittent turning of hard materials, the tool life is improved due to the use of fillers (cleaners), which represent the additional material, mounted on the ends of workpieces of softer metals (a damper). This creates the most favorable conditions for damping of peak of stresses during cutting, as well as the conditions under which the chips, blocked on a damper, contribute to cleaning the rake face of the tool from pickups of material being machined, thereby increasing wear resistance during the machining process.

To reduce the peak stresses arising in cutting-in of ceramic tool in the machining area and to increase its reliability in cutting steels characterized by improved hardness (HRC 58) after complete heat treatment, it is proposed to use a special damping device (Fig. 3). The damping device is able not only to reduce the peak stresses occurring in tool cutting-in but also to reduce vibrations arising in the process of tool cutting-in into the machining area.

A workpiece was machined under the following cutting modes: $V_{c}=600 \mathrm{~m} / \mathrm{min}, f=0.1 \mathrm{~mm} / \mathrm{rev}, a_{p}=0.1-0.25 \mathrm{~mm}$. Cutting modes of the experiment correspond to the earlier proposed ones, since they are most suitable to ensure roughness. The experiment applied the tool holders with mechanical fastening of ceramic cutting inserts of increased rigidity in longitudinal turning of workpieces of hardened 
steels C90E2U, C45, 37Cr4 with hardness of HRC 48-52. The geometric parameters of the cutting edge of cutters with mechanical fastening of ceramic cutting inserts were as follows: $K=75^{\circ} ; K_{1}=15^{\circ} ; \gamma=\alpha=5^{\circ} ; \lambda=0$ with cutting insert edge radius of $r=0.8 \mathrm{~mm}$.

The use of a damping device can have a positive effect on the thermal state of the tool due to redistribution of heat flows, since when the damping device is applied, the conditions for brittle fracture of ceramic cutting inserts virtually disappear, and given high heat resistance of ceramics and high resistance to thermal stresses, ceramic cutting inserts will maintain their performance.

The intensification of cutting modes and, primarily, an increase in the cutting speed causes an increase in heat generated in the cutting area; however, at the same time, it reduces the duration of the thermal cycle in the contact area of tool-workpiece.

It should be noted that in finishing intermittent turning, heat is distributed into a workpiece only to a small depth (20-25 $\mu \mathrm{m})$, and at considerably small depth, considerable temperature gradient occurs (decrease of temperature from $700-800$ down to $150-100^{\circ} \mathrm{C}$ ). It is also observed that with increase in intermittency of machining, the temperature gradient decreases [24].

A disc with width of $10-15 \mathrm{~mm}$, the material being selected experimentally, was used as a damper to damp peak vibrations in cutting-in into a workpiece being machined. When selecting rational properties of the material for the damping disk, the following materials were used: alloys $\mathrm{Al}$, steel $\mathrm{C} 45$ and cast iron FGL150. Meanwhile, the experiments have revealed the following:

When aluminum-based alloy was used as a damper, the experiments showed low efficiency. So, due to its high plasticity and extremely low elasticity, aluminum alloy is characterized by low efficiency because of its extremely high viscosity. During its use, the experiments also revealed a decrease in machining accuracy because of violation of rounded shape of a workpiece.

A bit different pattern was observed in turning of steel. In particular, it was observed that while cutting steels with low content of carbon and, respectively, high content of ferrite, the material shows high tendency to form pickups, consisting of particles of the material being machined, on ceramic areas of ceramic cutting inserts. Pickups sharply intensify the wear process, especially wear of flank face of cutting insert, and this wear process is accompanied by tear-outs of considerable extensive ceramic fragments, some of which are "embedded" in pickups, thus enhancing abrasion wear of flank faces of cutting inserts in the form of microscratching with tornout fragments of ceramic material, "embedded" in pickups. With the increase of content of carbon in steel, the proportion of cementite in its composition also increases. That results in reduction of adhesion and increase of abrasion tool wear.

The study has also assessed the possibility to use a disk made of steel C45 and cast iron FGL150 as a damping device, whose diameter corresponds to the diameter of the workpiece being machined. Castings of steel C45 are characterized by more homogeneous structure which is not prone to the formation of holes and solids, unlike castings of cast iron, characterized by modified properties of surface layer, resulting in extreme loading conditions. In this regard, the use of cast iron FGL150 produces negative results because of increased wear of ceramic inserts and increased spreads of wear resistance, as well as the tendency of ceramic inserts to brittle fracture.

Thus, for manufacture of a damping disk, steel C45 is the most suitable material from the viewpoint of removing the peak stresses in tool cutting-in. It should be noted that the use of a damper under the conditions of mechanical machining is a reasonable index of reliability at constant values in the function of controlling the performance and quality of mechanical machining of hard materials. While using the methods described earlier, the study also included the statistical processing of the results of the studies of tool life of cutting tool.

\subsection{Determination of level of tool reliability in machining under damping conditions}

In this regard, in accordance to the methodology, the study involved the tests concerning the dependence of flank wear land of tool of $\mathrm{Al}_{2} \mathrm{O}_{3}$ - $\mathrm{TiC}$ under damping conditions, as presented in Figure 4 . In this case, the cutting modes were as follows: $V_{c}=600 \mathrm{~m} / \mathrm{min}, f=0.1 \mathrm{~mm} / \mathrm{rev}, a_{p}=0.1 \mathrm{~mm}$.

Comparative characteristics of the cutting process with damping allows noting the positive impact of damping conditions at maximum flank wear land $\mathrm{VB}_{c} \leq 0.1 \mathrm{~mm}$. It is observed that the use of damping system reduces failure of ceramic cutting tool at the moment of cutting-in by $19 \%$ and that is a favorable factor and a considerably significant method to increase the reliability of ceramic cutting tool due to less sharp increase in elastic deformations and forces active at the moment of tool cutting-in into a workpiece being machined.

As it follows from the results of the tests conducted, flank wear land $\mathrm{VB}_{c}$ has a considerably strong influence on the probability of failure of ceramic tool, and when flank wear land increases, the probability of tool failure increases considerably, and at wear limit of the tool of $\mathrm{VB}_{c} \geq 0.4 \mathrm{~mm}$, it reaches $100 \%$ (see Fig. 5). For the cutting process with damping of vibrations of a workpiece, the probability of failure of ceramic tool decreases considerably; however, at the critical value of tool wear $\mathrm{VB}_{c}$, the effect of damping is almost completely leveled.

Damping under conditions of mechanical machining represents a reasonable index of reliability under constant cutting conditions, which consists in the function of control over performance and quality of mechanical machining of hard materials. So, the maximum stresses are formed on contact areas of rake and flank faces of the ceramic tool, and this nature may cause formation of microcrack and tool failure as a result of brittle fracture and deterioration of its thermal state. It should be noted that to a greater degree, the nature of elastic deformations are affected by power load and not the thermal state of a ceramic tool [12]. In this case, the use of a damping device contributes to more favorable distribution of stresses arising during cutting-in, and to the full extent, the damping can be described as a compensating factor. 


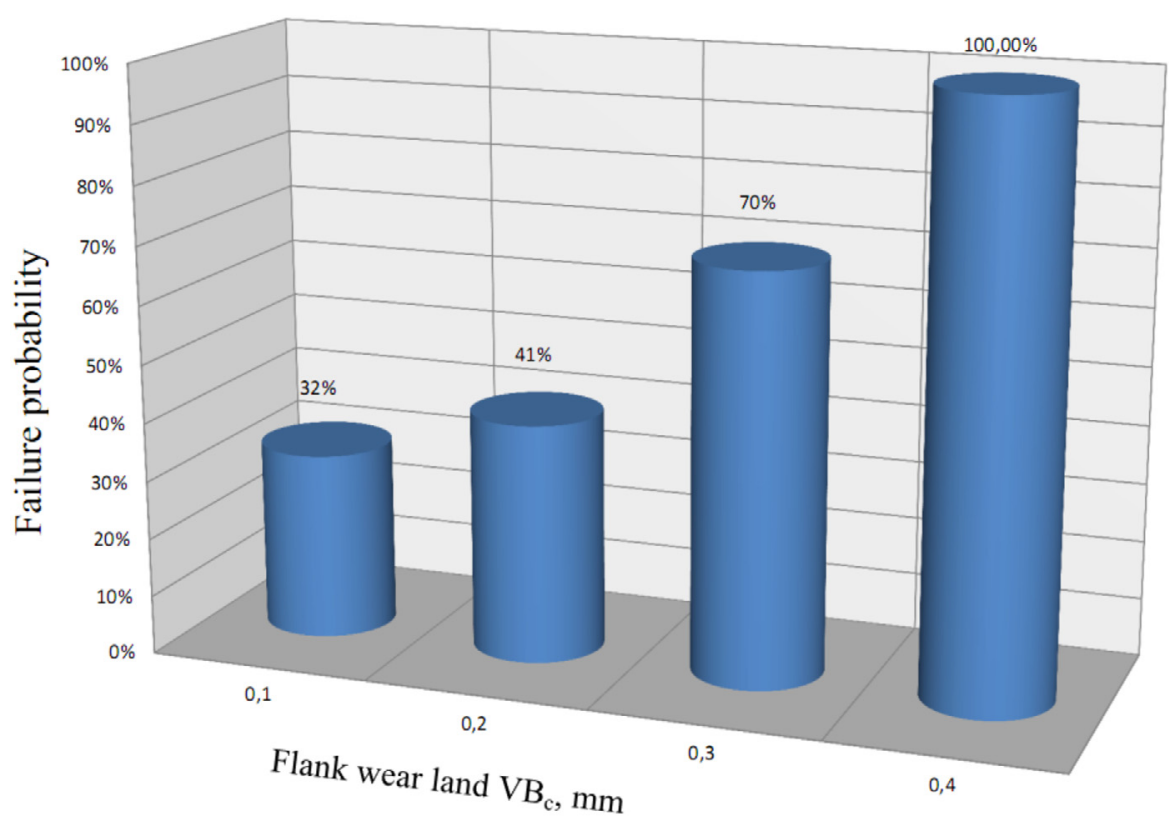

Fig. 4. Dependence of failure probability from flank wear land of mineral-ceramic tool of $\mathrm{Al}_{2} \mathrm{O}_{3}$ - $\mathrm{TiC}$ with a damper of steel $\mathrm{C} 45$.

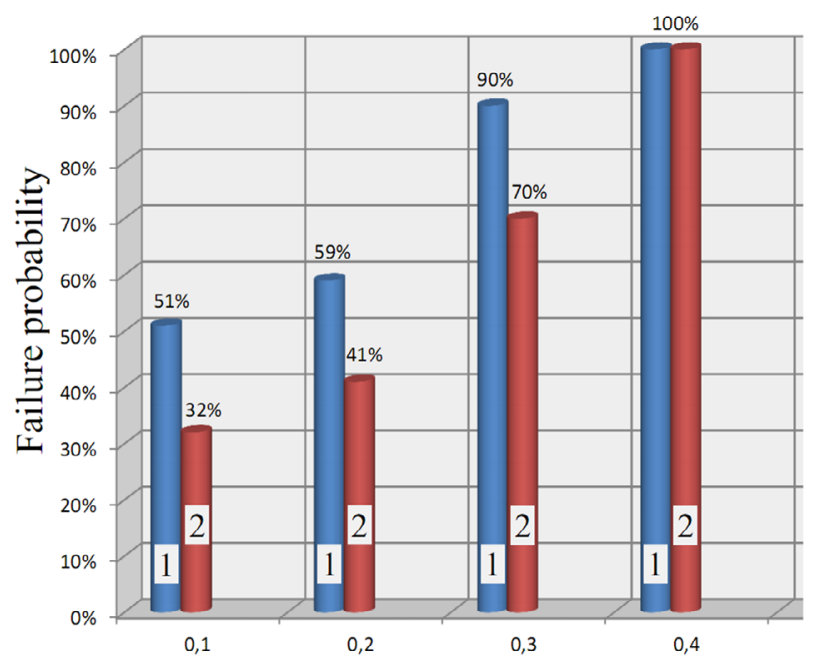

Fig. 5. Comparison of tool failure probability of flank wear land for options of standard cutting and cutting with damping of vibrations of a workpiece. 1 - tool of $\mathrm{Al}_{2} \mathrm{O}_{3}-\mathrm{TiC} ; 2$ - tool of $\mathrm{Al}_{2} \mathrm{O}_{3}-\mathrm{TiC}$ with damping.

It was also found that damping has a positive effect on errors arising during machining because of the increase in tool life of a ceramic tool and reduction of the probability of its failure because of brittle fracture of its cutting part. The growth of cracks slows down or even stops the cutting process due to the decrease in the level of local stresses.

Meanwhile, due to the low cost of material and low manufacturing costs, the use of a damper does not result in a noticeable increase in the cost of machining.

Due to positive results on reduction of tool failure (Fig. 5) with the use of damping of the processes of cuttingin and cutting, further tests were carried out to determine the time between failures to reveal the law distribution and calculation of the basic reliability parameters of the ceramic edge tool under conditions of damping in machining of hard materials.

The experimental data on evaluation of operational reliability have determined range of variation, range of specific interval, interval scale of interval variation series, frequency of random variable falling into specific interval, frequency of random variable $r_{j}$ falling into specific interval, proportionate frequency of random variable $p_{j}$ falling into specific interval and accumulated proportionate frequency $S\left(p_{j}\right)$. The data obtained were used to determine the average time between failures, mean square deviation and coefficient of variation.

Coefficient of time between failures of ceramic tool $V$ reached 0.4. It is well known from the theory of reliability that if $V=0.5$, then the variation series obtained after the experiment will be subject to the law of Weibull distribution. The above suggests that at the arbitrary moment, the process of wear of the cutting tool moves from the stage of sudden failure (exponential law of distribution) to the stage of expected predictable failure (the law of Weibull distribution).

The above law is used in determining the level of product reliability during running-in and revealing time between failures of nonrepairable products and, in particular, the products in which failure occurs because of fatigue failure. These provisions may also be applied to the research of a ceramic tool.

According to the assumed methodology, let us determine the distribution law and calculate the basic parameters of tool reliability: $P(t), Q(t), a(t), \lambda(t)$, enter them in Table 2.

The table data were used to build curves shown in Figure 6 . The analysis of Figure 6 shows that in cutting of hardened steel C90E2U with ceramic tool under damping 


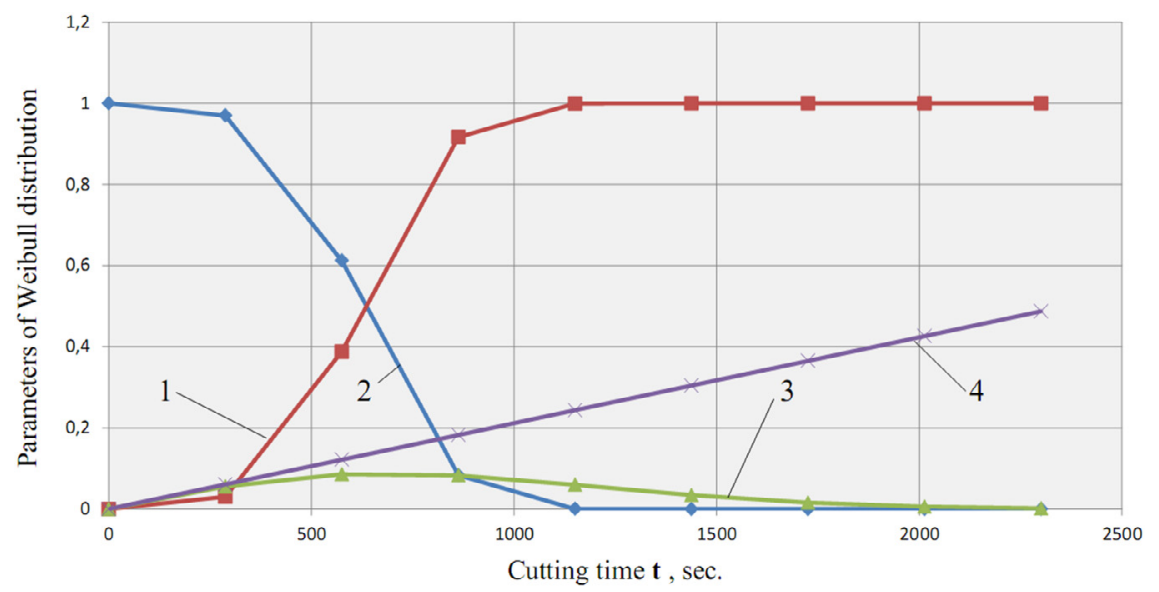

Fig. 6. Basic parameters of reliability of tool made of $\mathrm{CC} \mathrm{Al}_{2} \mathrm{O}_{3}$-TiC under conditions of damping machining of steel C90E2U at $a_{p}=0.2 \mathrm{~mm} ; f=0.1 \mathrm{~mm} / \mathrm{rev} ; V_{c}=600 \mathrm{~m} / \mathrm{min} .1-Q(t) ; 2-P(t) ; 3-a(t) \times 10^{2} ; 4-\lambda(t) \times 10^{2}$.

Table 2. Parameters of Weibull distribution, characterizing probability of failure of ceramic cutting inserts of $\mathrm{Al}_{2} \mathrm{O}_{3}-\mathrm{TiC}$ in longitudinal turning of hardened steel C90E2U (HRC 52-54) under conditions of damping.

\begin{tabular}{lllll}
\hline$t(\mathrm{~s})$ & $P(t)$ & $Q(t)$ & $a(t)$ & $\lambda(t)$ \\
\hline 0 & 1 & 0 & 0 & 0 \\
287.5667 & 0.969818 & 0.030182 & 0.0558 & 0.0609 \\
575.1333 & 0.612407 & 0.387593 & 0.0858 & 0.1218 \\
862.7 & 0.083539 & 0.916461 & 0.0831 & 0.1826 \\
1150.267 & 0.000391 & 0.999609 & 0.06 & 0.2435 \\
1437.833 & 0 & 1 & 0.0341 & 0.3044 \\
1725.4 & 0 & 1 & 0.0156 & 0.3653 \\
2012.967 & 0 & 1 & 0 & 0.4261 \\
2300.533 & 0 & 1 & 0 & 0.487 \\
\hline
\end{tabular}

conditions, predictability of failures increases and tool efficiency improves and that produces a positive impact on economic component of the machining process.

Figure 7 suggests that it is reasonable to use conditions of damping of vibration processes in cutting-in and operation of ceramic tools in automated production.

\subsection{Study of parameters of reliability of coated tool under conditions of damping of cutting process}

After obtaining the positive results in reduction of tool failure with the use of a damping device, further studies were conducted to determine the time between failures with the use of edge tool with nanostructured multilayered coating under damping conditions.

To understand the influence of developed nanostructured multilayered composite coatings on the basis of systems Ti-(TiAl)N-(TiAlCr)N, Ti-TiAlN-(ZrNbTiAl)N, the tests were carried out. Their results are presented in Figure 8.
It is observed that the application of coatings Ti-(TiAl)N-(TiAlCr)N and Ti-TiAlN-(ZrNbTiAl)N, obtained through the use of filtered cathodic vacuum arc deposition processes [25-31], has a positive effect on the reliability of the cutting tool; however, with regard to the degree of influence on the reliability, it is inferior to the options of cutting with the use of damping of vibration processes.

To determine the effect of cutting with the tool, equipped with cutting inserts of $\mathrm{CC} \mathrm{Al}_{2} \mathrm{O}_{3}-\mathrm{TiC}$ with developed nanostructured multilayered coatings $\mathrm{Ti}-(\mathrm{TiAl})$ $\mathrm{N}-(\mathrm{TiAlCr}) \mathrm{N}$ and Ti-TiAlN-(ZrNbTiAl)N under the conditions of damping, the tests were carried out, whose results are presented below.

As a result of the cutting with ceramic cutting tool with developed coatings and damping, as well as the result of the research of transformation of the basic parameters of the functioning of cutting system and tool wear, it was found that due to a decrease in thermomechanical stresses, acting on the ceramic tool, the mean time between failures increases.

On the basis of the obtained data, the study has determined the coefficients of tool failure variations for specified cutting conditions, which reached 0.3 and 0.35 , respectively. The decrease in the numeric value of the coefficient of variation means more predictable tool failure and, consequently, an increase in yield of workpieces machined, especially with regard to the conditions of the automated machining on CNC machines.

Thus, the damping of peak stress values (especially during tool cutting-in) in finishing of hardened steels with ceramic tool of $\mathrm{Al}_{2} \mathrm{O}_{3}-\mathrm{TiC}+(\mathrm{Ti}-(\mathrm{TiAl}) \mathrm{N}-(\mathrm{TiAlCr}) \mathrm{N})$ and $\mathrm{Al}_{2} \mathrm{O}_{3}-\mathrm{TiC}+(\mathrm{Ti}-\mathrm{TiAlN}-(\mathrm{ZrNbTiAl}) \mathrm{N})$ contributes to an increase in the reliability of the performance of the ceramic tool because of a decrease in the coefficient of variation and respective improvement in the predictability of tool failures.

As was discussed earlier, due to the nature of its physical and mechanical properties, a tool made of CC has a tendency to form a front of microcracks, whose 
(a)

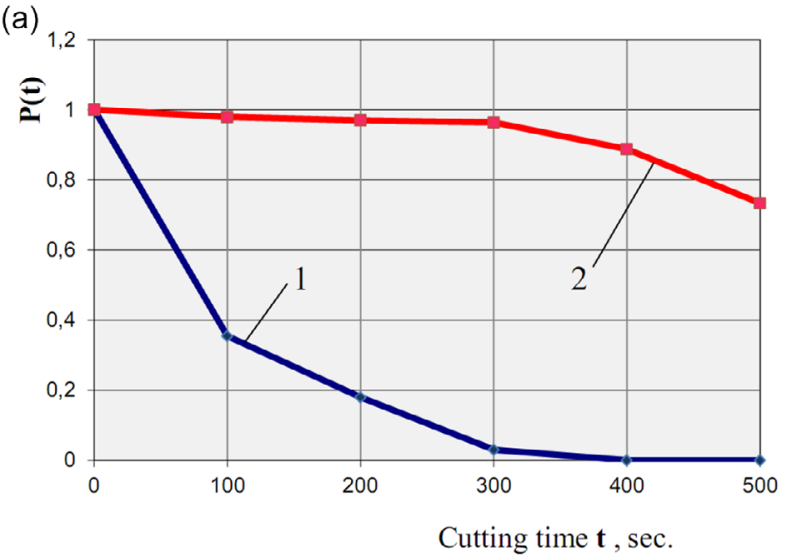

(b)

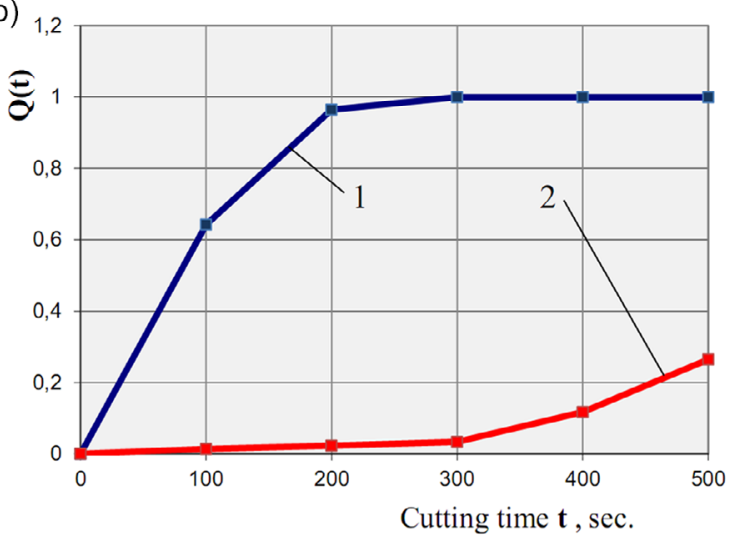

(c)

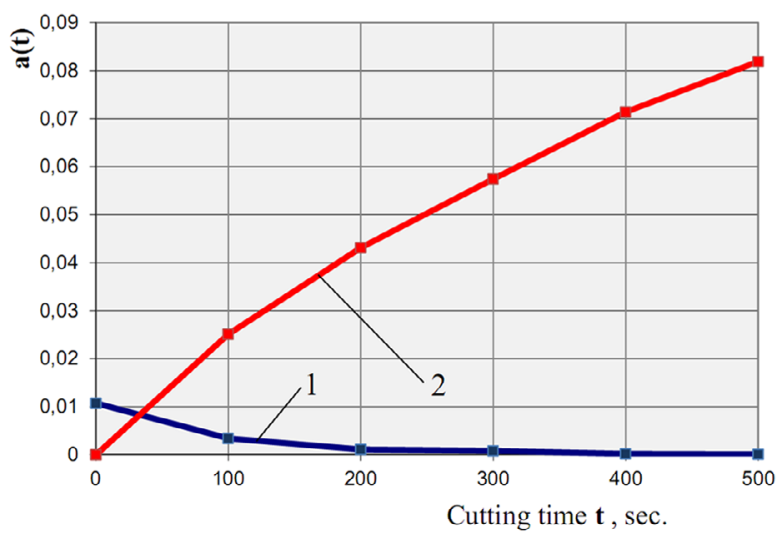

(d)

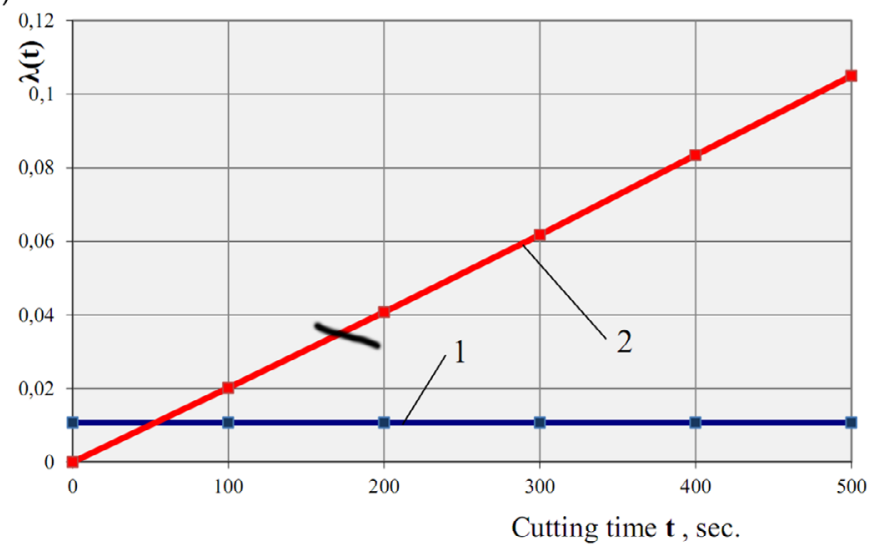

Fig. 7. Comparative characteristics of basic parameters of reliability of tool made of $\mathrm{CC} \mathrm{Al}_{2} \mathrm{O}_{3}$-TiC without damping and under conditions of damping machining of steel C90E2U at $a_{p}=0.2 \mathrm{~mm} ; f=0.1 \mathrm{~mm} / \mathrm{rev} ; V_{c}=600 \mathrm{~m} / \mathrm{min}$. a - probability of failure-free operation; $b$ - probability of failures; $c$ - failure flow; $d$ - failure rate depending on time. 1 - tool of $\mathrm{Al}_{2} \mathrm{O}_{3}-\mathrm{TiC}_{2} 2-$ tool of $\mathrm{Al}_{2} \mathrm{O}_{3}-\mathrm{TiC}$ with damping.

development and branching becomes a major cause of subsequent micro- and macrofailure of contact areas of tool surfaces.

Cracks formed in ceramic inserts are of different nature and may occur simultaneously or differentially. Types of cracks occurring depend on the machining conditions and cutting parameters.

The tests were conducted to study transformation of reliability parameters of ceramic tool with developed nanostructured multilayered coatings and damping system of finishing machining of hardened steels of enhanced hardness with a tool through combined techniques to improve reliability.

The methodology of the study included the following:

- Identification of the distribution law of failures of ceramic tools,

- Calculations of the main indicators of reliability $-P(t)$, $Q(t), a(t), \lambda(t)$

- Development of curve dependences.

The basic parameters of the reliability of a ceramic tool made of $\mathrm{CC} \mathrm{Al}_{2} \mathrm{O}_{3}$-TiC with developed nanodispersed multilayered composite coatings, calculated by the proposed methods, are presented in Tables 3 and 4 and in Figures 9-12.
On the basis of the table data, curves can be developed as shown in Figures 9-12.

The analysis of the presented data shows that for machining of hardened steel under the conditions of damping with a tool of $\mathrm{Al}_{2} \mathrm{O}_{3}-\mathrm{TiC}+(\mathrm{Ti}-(\mathrm{TiAl}) \mathrm{N}-$ $(\mathrm{TiAlCr}) \mathrm{N})$ and $\mathrm{Al}_{2} \mathrm{O}_{3}-\mathrm{TiC}+(\mathrm{Ti}-\mathrm{TiAlN}-(\mathrm{ZrNbTiAl}) \mathrm{N})$, predictability of tool failure increases, and an increase in the basic criteria of its reliability can be observed. The above proves the advisability of application of the developed system of finishing of hardened steels of enhanced hardness, including the use of a ceramic tool with coatings developed under conditions of damping in automated production.

The wear of cutting tool is a stochastic process defined by random nature of interaction of tool contact areas with the materials being machined and the state of the technological scheme. After deposition on the tool surface of nanostructured multilayered coatings of developed composition and machining of a workpiece under the conditions of damping, the predictability of failure increases significantly. Thus, it is possible to predict the criterion of reliability and the time at which brittle failure occurs in cutting ceramic in the modification of its surface layer through application of nanostructured multilayered coatings. 

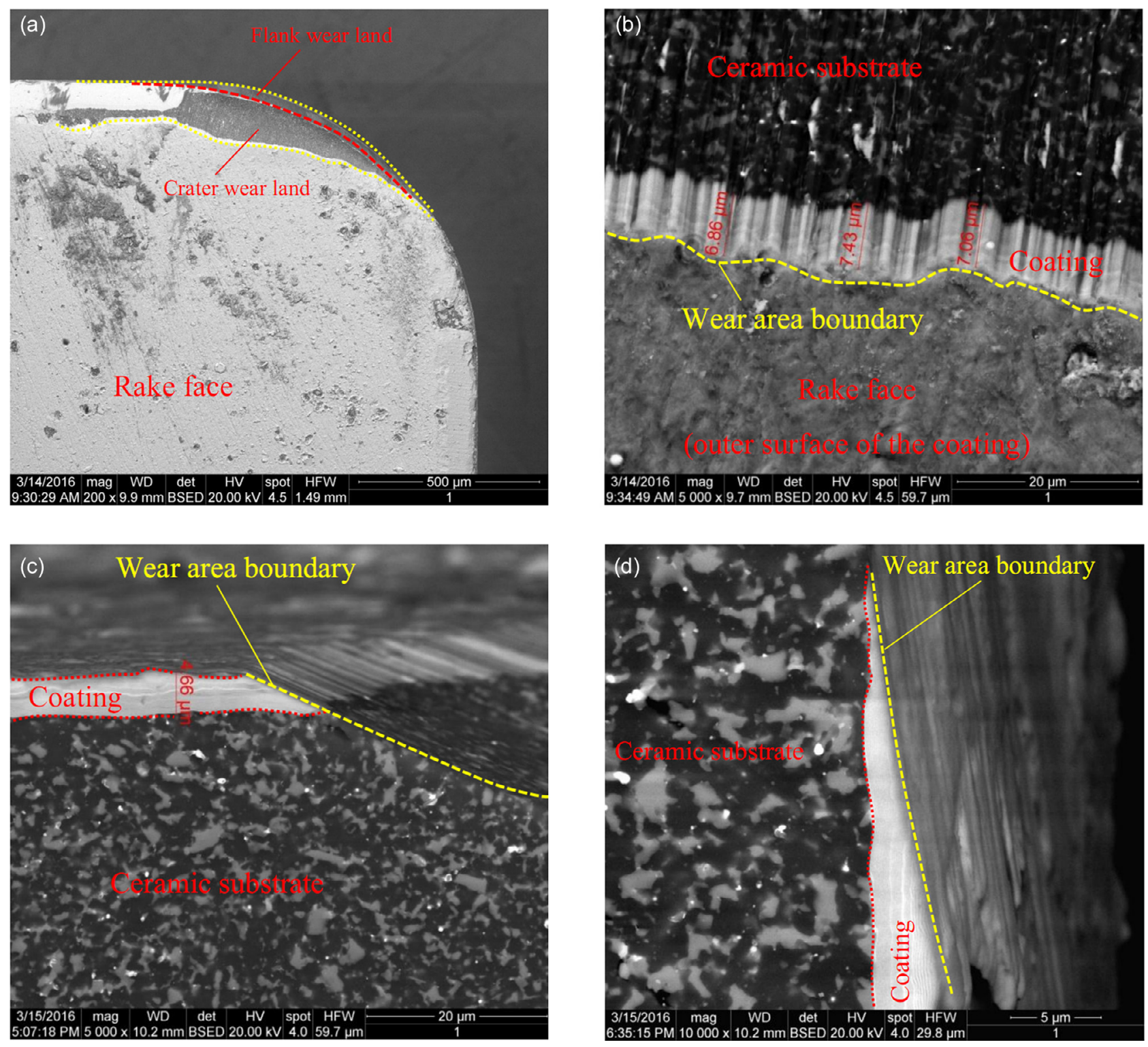

Fig. 8. Nature of wear of contact areas of rake and flank faces of cutting inserts of $\mathrm{Al}_{2} \mathrm{O}_{3}$ - TiC $+\mathrm{Ti}-\mathrm{TiAlN}-(\mathrm{ZrNbTiAl}) \mathrm{N}$ after $12 \mathrm{~min}$ of cutting with damping of a workpiece of hardened steel C45 HRC 52 at $V_{c}=600 \mathrm{~m} / \mathrm{min} ; f=0.1 \mathrm{~mm} / \mathrm{rev} ; a_{p}=0.15 \mathrm{~mm}$. a - general view of wear on rake face; $b$ - nature of wear of coating and of ceramic substrate on rake face; $c$ - type of wear of coating and substrate on rake face at cross-cut section; $\mathrm{d}$ - type of wear of coating and substrate on flank face at cross-cut section.

Table 3. Basic parameters of reliability of Weibull distribution $\mathrm{Al}_{2} \mathrm{O}_{3}-\mathrm{TiC}+(\mathrm{Ti}-(\mathrm{TiAl}) \mathrm{N}-(\mathrm{TiAlCr}) \mathrm{N})$ under damping conditions.

\begin{tabular}{lllll}
\hline$t(\mathrm{~s})$ & $P(t)$ & $Q(t)$ & $a(t)=f(t)$ & $\lambda(t)$ \\
\hline 0 & 1 & 0 & 0 & 0 \\
342.72 & 0.98 & 0.01 & 0.000286 & 0.000301 \\
685.45 & 0.84 & 0.15 & 0.00049 & 0.000603 \\
1028.19 & 0.42 & 0.57 & 0.000568 & 0.000904 \\
1370.92 & 0.06 & 0.93 & 0.000528 & 0.001206 \\
1713.64 & 0.001 & 0.99 & 0.000414 & 0.001507 \\
2056.38 & 0 & 0.99 & 0.000282 & 0.001809 \\
2399.11 & 0 & 1 & 0.000168 & 0.002111 \\
2741.84 & 0 & 1 & 0 & 0.002411 \\
\hline
\end{tabular}

Table 4. Basic parameters of reliability of Weibull distribution $\mathrm{Al}_{2} \mathrm{O}_{3}-\mathrm{TiC}+(\mathrm{Ti}-\mathrm{TiAlN}-(\mathrm{ZrNbTiAl}) \mathrm{N})$ under damping conditions.

\begin{tabular}{lllll}
\hline$t(\mathrm{~s})$ & $P(t)$ & $Q(t)$ & $a(t)=f(t)$ & $\lambda(t)$ \\
\hline 0 & 1 & 0 & 0 & 0 \\
368.09 & 0.97 & 0.0235 & 0.0388 & 0.0419 \\
736.19 & 0.68 & 0.31 & $0, .0616$ & 0.0838 \\
1104.28 & 0.145 & 0.85 & 0.0628 & 0.1258 \\
1472.38 & 0.00225 & 0.99 & 0.0488 & 0.1677 \\
1840.48 & 0 & 1 & 0.305 & 0.2096 \\
2208.57 & 0 & 1 & 0.0156 & 0.2515 \\
2576.67 & 0 & 1 & 0.00669 & 0.2935 \\
2944.77 & 0 & 1 & 0.002403 & 0.3354 \\
\hline
\end{tabular}




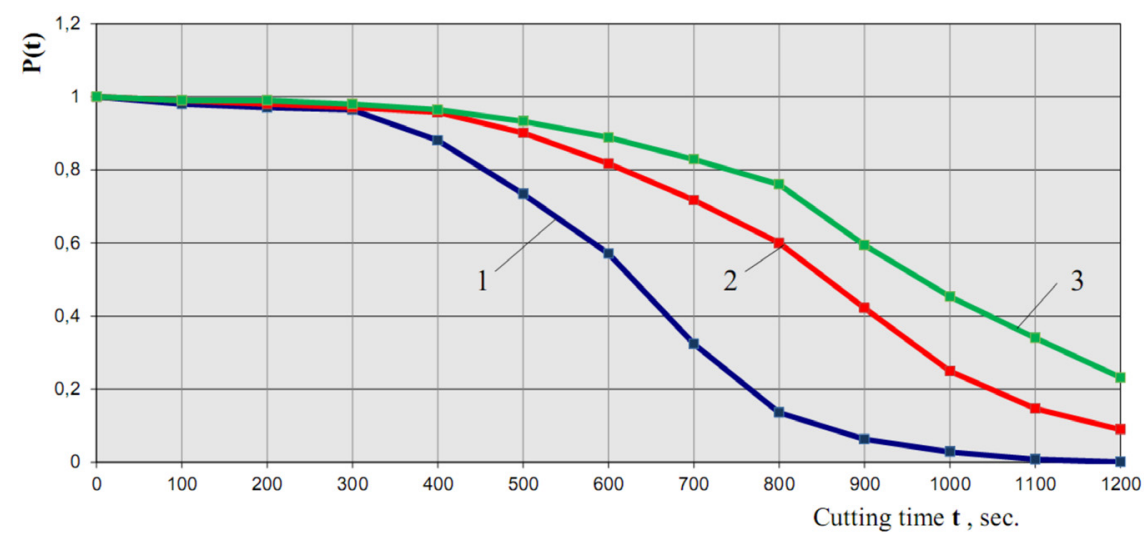

Fig. 9. Dependence of probability of failure-free operation from time. 1 - tool of $\mathrm{Al}_{2} \mathrm{O}_{3}-\mathrm{TiC}_{\text {with damping; }} 2$ - tool of $\mathrm{Al}_{2} \mathrm{O}_{3}$ - TiC + (Ti-TiAlN-(ZrNbTiAl)N) with damping; 3-tool of $\mathrm{Al}_{2} \mathrm{O}_{3}-\mathrm{TiC}+(\mathrm{Ti}-(\mathrm{TiAl}) \mathrm{N}-(\mathrm{TiAlCr}) \mathrm{N})$ with damping.

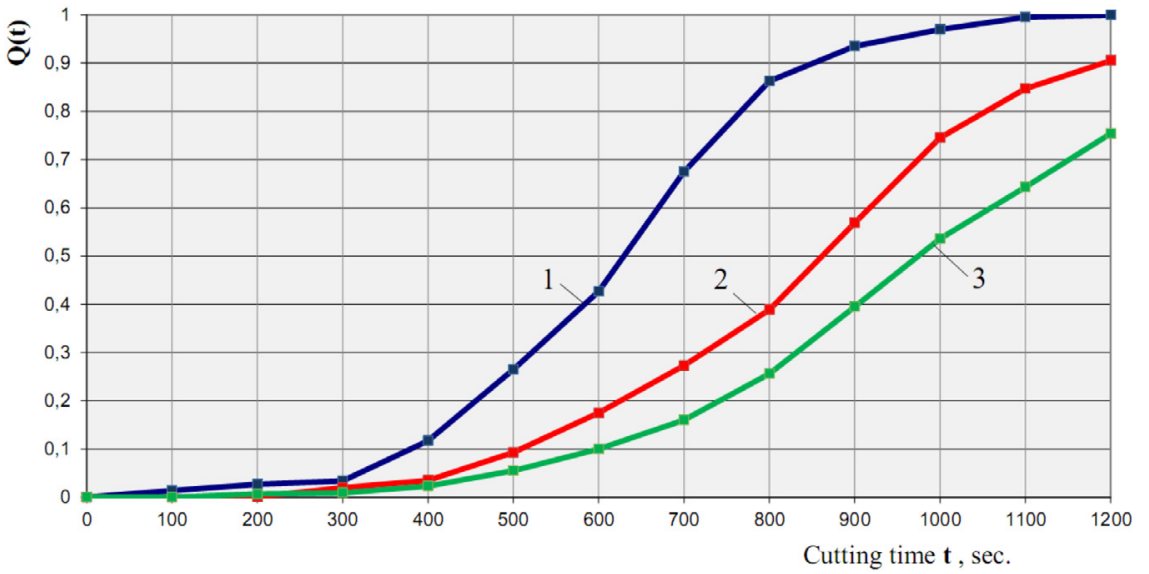

Fig. 10. Dependence of failure probability from time. 1 -tool of $\mathrm{Al}_{2} \mathrm{O}_{3}-\mathrm{TiC}$ with damping; $2-$ tool of $\mathrm{Al}_{2} \mathrm{O}_{3}-\mathrm{TiC}+(\mathrm{Ti}-\mathrm{TiAlN}-$ $(\mathrm{ZrNbTiAl}) \mathrm{N})$ with damping; 3 - tool of $\mathrm{Al}_{2} \mathrm{O}_{3}-\mathrm{TiC}+(\mathrm{Ti}-(\mathrm{TiAl}) \mathrm{N}-(\mathrm{TiAlCr}) \mathrm{N})$ with damping.

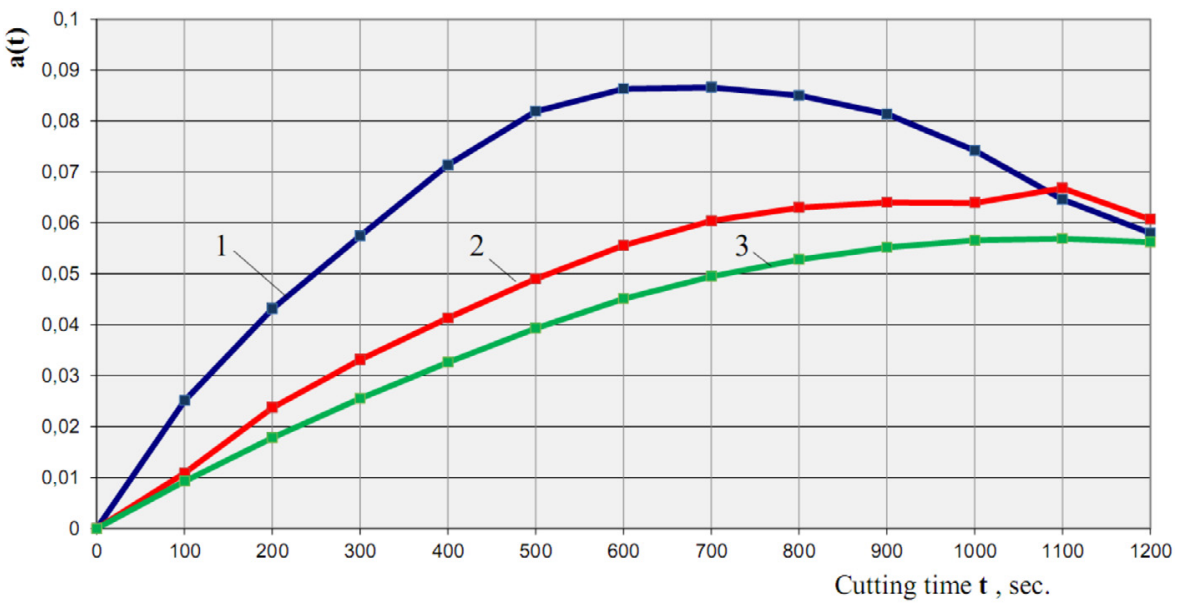

Fig. 11. Dependence of failure probability from cutting time. 1 - tool of $\mathrm{Al}_{2} \mathrm{O}_{3}-\mathrm{TiC}$ with damping; $2-$ tool of $\mathrm{Al}_{2} \mathrm{O}_{3}$ - TiC $+(\mathrm{Ti}-\mathrm{TiAlN}-$ $(\mathrm{ZrNbTiAl}) \mathrm{N})$ with damping; 3 - tool of $\mathrm{Al}_{2} \mathrm{O}_{3}-\mathrm{TiC}+(\mathrm{Ti}-(\mathrm{TiAl}) \mathrm{N}-(\mathrm{TiAlCr}) \mathrm{N})$ with damping. 


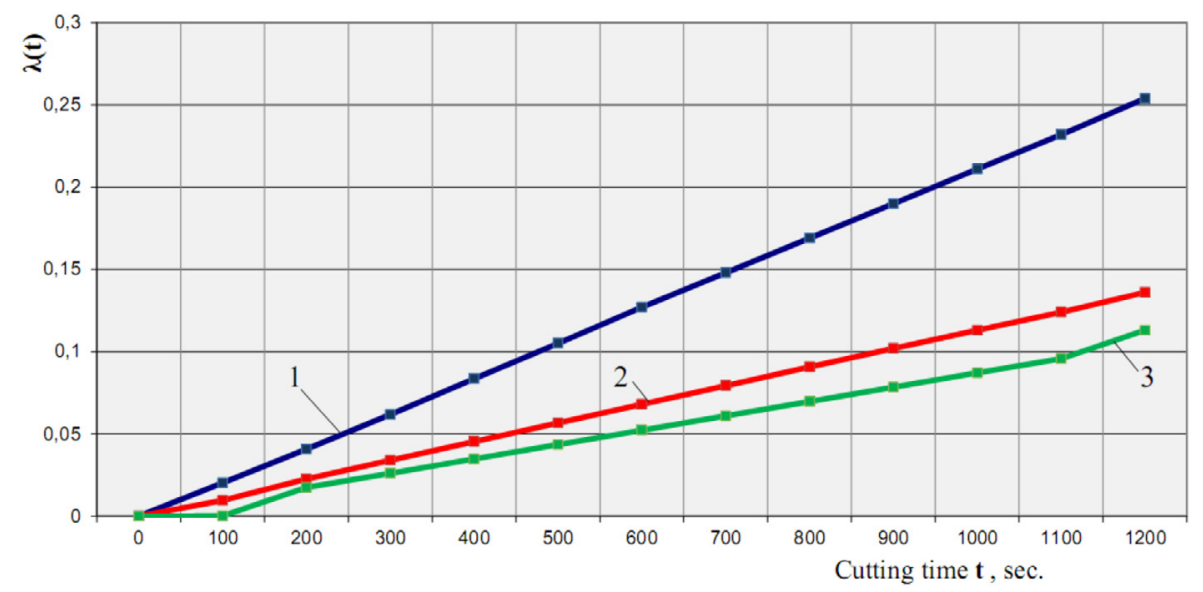

Fig. 12. Dependence of distribution flow from cutting time. 1 - tool of $\mathrm{Al}_{2} \mathrm{O}_{3}-\mathrm{TiC}$ with damping; $2-$ tool of $\mathrm{Al}_{2} \mathrm{O}_{3}$-TiC $+(\mathrm{Ti}-\mathrm{TiAlN}-$ $(\mathrm{ZrNbTiAl}) \mathrm{N})$ with damping; 3 - tool of $\mathrm{Al}_{2} \mathrm{O}_{3}-\mathrm{TiC}+(\mathrm{Ti}-(\mathrm{TiAl}) \mathrm{N}-(\mathrm{TiAlCr}) \mathrm{N})$ with damping.

\section{Conclusions}

A damping device is developed, which allows reducing peak stresses arising during cutting-in and providing improved reliability of ceramic tools.

It is observed that the use of a device with damping element made of steel C45 characterized by hardness lower than the material being machined results in reduction and stabilization of peak stresses arising at cutting-in of ceramic tool into the machining area. It is shown that damping of peak stresses and vibration processes arising at cutting-in of a ceramic tool and cutting of hardened steels of enhanced hardness is an effective way to improve the reliability of ceramic tool due to the reduction of probability of failures.

The specifics of the parameters of the performance of finishing of hardened steels with a tool of mixed ceramics with the proposed nanostructured multilayered coatings was studied under the conditions of damping, which showed the improvement of the functional parameters of cutting.

It is observed that the formation of modifying coatings on an edge ceramic tool in machining of hardened steels with HRC > 50 under the conditions of damping can reduce the coefficient of tool failure variation down to 0.3 and that improves the ability to predict failure of ceramic tools and allows recommending ceramic tools for the use in automated production.

\section{Nomenclature}

$\mathrm{CC} \quad$ Cutting ceramic

CF Cutting fluid

MTWS Machine-tool-workpiece system

$v_{\mathrm{c}} \quad$ Cutting speed

$f \quad$ Feed

$a_{\mathrm{p}} \quad$ Depth of cut

$\mathrm{VB}_{c} \quad$ Flank wear land

$A_{\mathrm{p}} \quad$ Specific work of plastic deformation

$\sigma_{\gamma}, \tau_{\gamma} \quad$ Contact stresses

$\begin{array}{ll}\gamma & \text { Rake angle } \\ \alpha & \text { Clearance angle } \\ K, K_{1} & \text { Major tool cutting edge angle, minor tool cutting } \\ & \text { edge angle } \\ \lambda & \text { Inclination angle } \\ r & \text { Edge radius } \\ r_{j} & \text { Frequency of random variable falling into specific } \\ & \text { interval } \\ p_{j} & \text { Proportionate frequency of random variable } \\ S\left(p_{j}\right) & \text { falling into specific interval } \\ V & \text { Accumulated proportionate frequency } \\ t & \text { Coefficient of variation of failure time } \\ P(t) & \text { Time (s) } \\ Q(t) & \text { Probability of failure-free operation } \\ a(t) & \text { Probability of failure } \\ \lambda(t) & \text { Failure flow parameter }\end{array}$

Acknowledgment. This research was financed by the Ministry of Education and Science of the Russian Federation in the framework of the state order in the sphere of scientific activity (Leading researchers, project 16.9575.2017/6.7).

\section{References}

[1] R. Riedel, Handbook of ceramic hard materials, Wiley-VCH Verlag GmbH, Weinheim, Germany, 2000

[2] L.N. López de Lacalle, A. Lamikiz, Machine tools for high performance machining, Springer, Berlin, 2009

[3] E.S. Sotova, A.A. Vereshchaka, A.S. Vereshchaka, Ceramic cutting tools, MSTU "STANKIN", Moscow, 2013 (in Russian)

[4] E. Brinksmeier, S. Bartsch, Ceramic tools - material and load types determine wear mechanisms, Ann. CIRP 37 (1988) 97-100

[5] A.K.M.N. Amin, U.A.K.B. Mohamad, M.D. Arif, Implementation of magnetic damping to reduce chatter amplitude and tool wear during turning of stainless steel AISI 304, Appl. Mech. Mater. 607 (2014) 171-175

[6] A.K.M.N. Amin, U.A.K.B. Mohamad, M.D. Arif, A.G.B.A. Muthalif, Comparison vibration amplitude for magnetic damping in turning of stainless steel AISI 304, Appl. Mech. Mater. 394 (2013) 251-255 
[7] G. Aguirre, M. Gorostiaga, T. Porchez, J. Muñoa, Selftuning semi-active tuned-mass damper for machine tool chatter suppression, in: Proceedings of the International Conference on Noise and Vibration Engineering, 2012, pp. 109-123

[8] Y. Yang, J. Muñoa, Y. Altintas, Optimization of multiple tuned mass dampers to suppress machine tool chatter, Int. J. Mach. Tools Manuf. 50 (2010) 834-842

[9] M. Martins da Silva, G.S. Venter, P.S. Varoto, R.T. Coelho, Experimental results on chatter reduction in turning through embedded piezoelectric material and passive shunt circuits, Mechatronics 29 (2015) 78-85

[10] S. Murakami, Mechanical modeling of material damage, Appl. Mech. 55 (1988) 280-286

[11] R. Dornhöfer, Feindrehen von unlegierten Kohlenstoffstählenmit Keramik- und Hartmetallwerkzeugen, Freiflächenverschleiß und Oberflächengüte, Dissertation, TH Braunschweig, 1961 (in German)

[12] Ye. Ya. Litovskiy, F.S. Katan, S.L. Bondarenko, Changes in the structure and thermal properties of quartz ceramics in the process of rapid heating, Ogneupory 11 (1986) 42-46 (in Russian)

[13] S.N. Grigoriev, A.A. Vereschaka, A.S. Vereschaka, A.A. Kutin, Cutting tools made of layered composite ceramics with nanoscale multilayered coatings, Procedia CIRP 1 (2012) 318-323

[14] A.S. Vereschaka, S.N. Grigoriev, E.S. Sotova, A.A. Vereschaka, Improving the efficiency of the cutting tools made of mixed ceramics by applying modifying nano-scale multilayered coatings, Adv. Mater. Res. 712-715 (2013) 391-394

[15] A.S. Vereschaka, S.N. Grigoriev, V.P. Tabakov, E.S. Sotova, A.A. Vereschaka, M. Yu. Kulikov, Improving the efficiency of the cutting tool made of ceramic when machining hardened steel by applying nano-dispersed multi-layered coatings, Key Eng. Mater. 581 (2014) 68-73

[16] A.A. Vereshchaka, E.S. Sotova, A.D. Batako, M.I. Sedykh, A.S. Vereshchaka, A study of the cutting properties and wear mechanism of ceramic edge tools with nanostructure multilayer composite coatings, J. Friction Wear 35 (2014) 483-488

[17] A.A. Vereshchaka, A.D. Batako, E.S. Sotova, A.S. Vereshchaka, Nanostructured multilayer composite coatings on ceramic cutting tools for finishing treatment of highhardness quenched steels, Metal Sci. Heat Treat. 57 (2016) 614-621

[18] A. Vereschaka, J. Prilukova, B. Mokritskii, A. Vereschaka, N. Sitnikov, Specifics of application of cutting ceramics with functional coating in turning of high-strength materials, Mater. Sci. Forum 857 (2016) 221-227
[19] A.G. Evans, Ceramics and ceramic composites as hightemperature structural materials: challenges and opportunities, in: R.T. Cahn, M. McLean, A. Evans (Eds.), HighTemperature Structural Materials, Springer, Berlin, 1996

[20] K. Weinert, I. Inasaki, J.W. Sutherland, T. Wakabayashi, Dry machining and minimum quantity lubrication, Ann. CIRP 53 (2004) 511-537

[21] J. Schmidt, Mechanische und thermische Wirkungen beim Drehen gehärteter Stähle, Dissertation, Universität Hannover, 1999 (in German)

[22] S. Seguy, L. Arnaud, T. Insperger, Chatter in interrupted turning with geometrical defects: an industrial case study, Int. J. Adv. Manuf. Technol. 75 (2014) 45-56

[23] J. Elias, N.V.N. Namboothiri, Cross-recurrence plot quantification analysis of input and output signals for the detection of chatter in turning, Nonlinear Dyn. 76 (2014) 255-261

[24] B. Karpuschewski, Sensoren zur Prozessüberwachung beim Spanen [Sensors for process monitoring in cutting], Habilitation, Universität Hannover, 2001 (in German)

[25] A.A. Vereshchaka, A.S. Vereshchaka, O. Mgaloblishvili, M.N. Morgan, A.D. Batako, Nano-scale multilayeredcomposite coatings for the cutting tools, Int. J. Adv. Manuf. Technol. 72 (2014) 303-317

[26] A.A. Vereschaka, S.N. Grigoriev, N.N. Sitnikov, A. Batako, Delamination and longitudinal cracking in multi-layered composite nano-structured coatings and their influence on cutting tool life, Wear 390-391 (2017) 209-219

[27] A.A. Vereschaka, S.N. Grigoriev, Study of cracking mechanisms in multi-layered composite nano-structured coatings, Wear 378-379 (2017) 43-57

[28] A.O. Volkhonskii, A.A. Vereshchaka, I.V. Blinkov, A.S. Vereshchaka, A.D. Batako, Filtered cathodic vacuum arc deposition of nanolayered composite coatings for machining hard-to-cut materials, Int. J. Adv. Manuf. Technol. 84 (2016) 1647-1660

[29] A.S. Vereschaka, A.A. Vereschaka, D.V. Sladkov, A. Yu. Aksenenko, N.N. Sitnikov, Control of structure and properties of nanostructured multilayer composite coatings applied to cutting tools as a way to improve efficiency of technological cutting operation, J. Nano Res. 37 (2016) 51-57

[30] S.N. Grigoriev, A.A. Vereschaka, S.V. Fyodorov, N.N. Sitnikov, A.D. Batako, Comparative analysis of cutting properties and nature of wear of carbide cutting tools with multi-layered nano-structured and gradient coatings produced by using various deposition methods, Int. J. Adv. Manuf. Technol. 90 (2017) 3421-3435

[31] A.A. Vereschaka, M.A. Volosova, A. Batako, A.S. Vereschaka, N.N. Sitnikov, A.E. Seleznev, Nano-scale multi-layered coatings for improved efficiency of ceramic cutting tools, Int. J. Adv. Manuf. Technol. 90 (2017) 27-43

Cite this article as: A. Vereschaka, B. Mokritskii, A. Krapostin, N. Sitnikov, G. Oganyan, Improvement reliability of cutting ceramic through use of damping system and nanostructured multilayered composite coatings, Mechanics \& Industry 19, $606(2018)$ 